\title{
Review: parental smoking increases risk of recurrent otitis media, middle ear effusion, and tonsillectomy or adenoidectomy in children
}

\author{
Strachan DP, Cook DG. Parental smoking, middle ear disease and adenotonsillectomy in children. Thorax 1998 Feb;53:50-6.
}

\section{Question}

Is parental smoking associated with acute and recurrent otitis media, middle ear effusion, and surgery for diseases of the ear, nose, and throat in children?

\section{Data sources}

Medline and Embase/Excerpta Medica were searched in April 1997 using the terms (or derivations of the terms) tobacco smoke pollution, passive, second-hand, second hand, involuntary, parent, maternal, mother, paternal, father, or household combined with the terms "smok," tobacco, or cigarette. The search was restricted to children according to textwords in the articles' titles or abstracts. Bibliographies of relevant overviews or studies were also reviewed.

\section{Study selection}

The abstracts of articles that had keywords relating to respiratory or allergic disease were reviewed $(n=1593)$. From these, 99 papers were identified that included the textwords (or derivations of) "tympanom," otitis, middle ear, glue ear, or tonsil.

\section{Data extraction}

Data were extracted on year, country, and design of study; sample size; age of children; outcome; case definition; and source of control or cohort samples.

\section{Main results}

45 papers relating to 42 studies were identified (13 studies on acute otitis media, 9 on recurrent otitis media, 5 on middle ear effusion, 9 on referrals for middle ear effusion, 4 on adenoidectomy or tonsillectomy, 1 on deafness, and 1 on postoperative natural history). The 13 studies on acute otitis media were not meta-analysed because of study variation. Based on meta- analysis, if either parent smoked, children had an increased risk of recurrent otitis media, middle ear effusion (based on tympanometry or otoscopy), and adenoidectomy or tonsillectomy (table). They were not at increased risk for referral or surgical intervention for middle ear effusion (table). 1 small study of 87 infants reported that infants who were passively exposed to cigarette smoke were more likely to show signs of hearing loss $(\mathrm{p}<0.05)$.

\section{Conclusion}

The children of parents who smoke are at increased risk of recurrent otitis media, middle ear effusion, and adenoidectomy or tonsillectomy. Pooled odds ratios (ORs) for recurrent otitis media, middle ear effusion,
adenoidectomy or tonsillectomy, and outpatient referral if either parent smoked

\begin{tabular}{|c|c|c|c|}
\hline Outcome & Number of studies & Pooled OR & $95 \% C I$ \\
\hline $\begin{array}{l}\text { Recurrent otitis } \\
\text { media }\end{array}$ & $\begin{array}{l}7 \\
\text { (4 cohort, } 2 \text { case } \\
\text { control, } 1 \text { survey) }\end{array}$ & $1.48^{*}$ & 1.08 to 2.04 \\
\hline Middle ear effusion & $\begin{array}{l}4 \\
\text { (3 cohort, } 1 \text { survey) }\end{array}$ & 1.38 & 1.23 to 1.55 \\
\hline $\begin{array}{l}\text { Adenoidectomy and } \\
\text { tonsillectomy }\end{array}$ & $\begin{array}{l}4 \\
\text { (2 case control, } \\
2 \text { surveys) }\end{array}$ & 2.07 & 1.82 to 2.35 \\
\hline Outpatient referral & $\begin{array}{l}7 \\
\text { (1 cohort, } 6 \text { case } \\
\text { control) }\end{array}$ & $1.21 \dagger$ & 0.95 to 1.53 \\
\hline
\end{tabular}

*Based on a random effects model. All other ORs based on a fixed effects model. $\dagger$ Not significant.

Source of funding: UK Department of Health.

For correspondence: Dr D P Strachan, Department of Public Health Sciences, St George's Hospital Medical School, Cranmer Terrace, London SW17 ORE, UK. Fax +44 (0)181 7253584.

\section{Commentary}

There are increasing public health concerns about the effects of passive tobacco smoke exposure. Clinical research is providing evidence that children who inhale secondhand smoke may have a higher incidence of health problems such as upper respiratory infections, otitis media, tonsillitis, aggravation of chronic respiratory conditions, and sudden infant death syndrome. ${ }^{1}$

The meta-analysis by Strachan and Cook clearly confirms the effect of environmental tobacco exposure on young children's risk of developing middle ear problems. This is consistent with a previous meta-analysis which concluded that use of tobacco products by adults increased childhood mortality and morbidity. ${ }^{2}$

The authors chose to include only published studies in their review. This exclusion could affect the conclusions of the review because of the potential for "publication bias" (ie, studies that are published are more likely to report statistically significant findings than are studies that are not accepted or submitted for publication). Of the 42 studies included in this review, 12 were cross sectional surveys. This is a weak study design because the data related to parental smoking (exposure) and middle ear disease (outcome) are collected at the same time making it difficult to establish causality. The analysis might have been strengthened by eliminating these studies.

Despite the variations in research designs, the analysis shows consistent results that link environmental tobacco exposure to paediatric middle ear conditions. There is limited research on the long term effects of middle ear problems. The authors caution that evidence relating parental smoking to adenoidectomy or tonsillectomy is sparse and heavily influenced by a single cross sectional study.

The study conclusions have important implications and broad applications for nurses. All nurses can raise public awareness of the problem. Nurses who practise in the fields of paediatrics, community health, and occupational health can reduce children's health risks by providing education and supportive counselling to parents who smoke and by lobbying for smoke free public buildings.

$$
\begin{array}{r}
\text { Cheryl Sams, RN, MSN } \\
\text { Clinical Nurse Specialist } \\
\text { Pediatric Medicine, } \\
\text { Hospital for Sick Children } \\
\text { Toronto, Ontario, Canada }
\end{array}
$$

1 Witschi H, Joad JP, Pinkerton KE. The toxicology of environmental tobacco smoke. Anпu Rev Pharmacol Toxicol 1997;37:29-52.

2 DiFranza JR, Lew RA. Morbidity and mortality in children associated with the use of tobacco products by other people. Pediatrics 1996;97: $560-8$ 